\title{
Correction to: Putting relational contract theory to the test: experimental evidence
}

\author{
Nisvan Erkal ${ }^{1}$ - Steven Y. Wu ${ }^{2}$ D $\cdot$ Brian E. Roe ${ }^{3}$
}

Published online: 29 March 2021

(c) Economic Science Association 2021

\section{Correction to: Experimental Economics https://doi.org/10.1007/s10683-021-09707-w}

Author corrections were partially completed and thus there was a need to include additional corrections which were missed.

Original article has been updated.

Publisher's Note Springer Nature remains neutral with regard to jurisdictional claims in published maps and institutional affiliations.

The original article can be found online at https://doi.org/10.1007/s10683-021-09707-w.

Steven Y. Wu

sywu@purdue.edu

Nisvan Erkal

n.erkal@unimelb.edu.au

Brian E. Roe

roe.30@osu.edu

1 Department of Economics, University of Melbourne, 111 Barry Street, Carlton, VIC 3010, Australia

2 Department of Agricultural Economics, Purdue University, Krannert Building, 403 West State Street, West Lafayette, IN 47907, USA

3 Department of Agricultural, Environmental and Development Economics, Ohio State University, 225 Agricultural Administration Building, 2120 Fyffe Road, Columbus, OH 43210, USA 